\title{
Two-Stage Bronchoscopic Endobronchial Valve Treatment Can Lead to Progressive Lung Volume Reduction and May Decrease Pneumothorax Risk
}

\author{
Thomas Egenod' \\ Jeremy Tricard ${ }^{2}$ \\ Romane Fumat ${ }^{3}$ \\ Yannick Simonneau' \\ Florent Favard ${ }^{4}$ \\ Marc-Samir Guillot ${ }^{5}$ \\ Samia Collot ${ }^{6}$ \\ Marion Dupuis ${ }^{3}$ \\ Boris Melloni ${ }^{1}$ \\ Alain Vergnenegre' \\ Nicolas Guibert ${ }^{3}$ \\ Matthieu Dusselier' \\ 'Pulmonology Department, Dupuytren \\ University Hospital, Limoges, France; \\ ${ }^{2}$ Thoracic Surgery Department, \\ Dupuytren University Hospital, Limoges, \\ France; ${ }^{3}$ Pulmonology Department, \\ Toulouse University Hospital, Toulouse, \\ France; ${ }^{4}$ Physiology Department, \\ Dupuytren University Hospital, Limoges, \\ France; ${ }^{5}$ Radiology Department, \\ Dupuytren University Hospital, Limoges, \\ France; ${ }^{6}$ Radiology Department, \\ Toulouse University Hospital, Toulouse, \\ France
}

Background: Since successful development of endobronchial valves (EBV) as treatment for severe emphysema, its main complication, pneumothorax, remains an important concern.

Objective: We hypothesized that a two-step EBV implantation, during two distinct iterative procedures could lead to a more progressive target lobe volume reduction (TLVR) and thus ipsilateral lobe re-expansion, resulting in a significant decrease in the pneumothorax rate.

Methods: This retrospective bi-center study carried out by Limoges and Toulouse University Hospitals included patients following the inclusion criteria established by the BLVR expert panel. All patients were treated by two distinct procedures: first, EBVs were placed in all but the most proximal segment or sub-segment. The remaining segment was treated subsequently. All patients had a complete evaluation before treatment, and 3 months after the second procedure.

Results: Out of 58 patients included, only 4 pneumothoraxes (7\%) occurred during the study. The other complications were pneumonia and severe COPD exacerbation $(8.6 \%$ and $13.7 \%$ of patients, respectively). Significant improvement was found for $\mathrm{FEV}_{1}(+19.6 \pm$ $25 \%)$, RV $(-468 \pm 960 \mathrm{~mL}), 6 \mathrm{MWD}(30 \pm 85 \mathrm{~m})$, BODE Index $(-1.4 \pm 1.8$ point $)$ and TLVR $(50.6 \pm 35.1 \%)$. Significant TLVR (MCID) was obtained in $74.1 \%$ of patients $(43 / 58)$.

Conclusion: This new approach using EBV could reduce the incidence of pneumothorax without increasing other complication rates. Clinical and physiological outcomes are similar to those reported in studies using the conventional single-step treatment.

Keywords: bronchoscopic lung volume reduction, pneumothorax, endobronchial valves, two-step EBV therapy

\section{Introduction}

Based on the positive outcomes of five randomized controlled trials (reviewed in ${ }^{1}$ ), bronchoscopic lung volume reduction (BLVR) using Zephyr ${ }^{\circledR}$ endobronchial valves (EBV - Zephyr EBV, PulmonX Corp.) is now a treatment option for a subgroup of patients with severe emphysema with little to no collateral ventilation $(\mathrm{CV}){ }^{2}$ According to a recent meta-analysis, the main (and potentially life-threatening) complication is pneumothorax, occurring in $23 \%$ of patients (14\% to $39 \%$ in trials), with a relative risk of $6.32 .{ }^{1}$ In addition, other complications include COPD exacerbation (9.3-64.0\%), pneumonia (11.7\%), valve migration and replacement rates $(1.5-20.0 \%)$, and mortality $(8 \%)$. Pneumothorax management can be long and challenging. The transient or permanent removal of at least one valve is often required, and 4 deaths directly imputable to EBVs have been reported in the 5 main
Correspondence: Thomas Egenod Pulmonology Department, Dupuytren University Hospital, Limoges, France Tel +33555056892

Fax +33555056815

Email thomas.egenod@chu-limoges.fr 
randomized trials in which 295 patients were treated. ${ }^{3}$ The exact mechanism of this side effect remains unclear. Two pathophysiological mechanisms have been previously described. First, rupture of blebs or bullae in the ipsilateral untreated lobe might occur due to sudden shifting of lung volumes. The presence of blebs or bullae has however not been identified as a risk factor for pneumothorax. ${ }^{4}$ Second, pneumothorax ex vacuo, due to a sudden increase in negative intra pleural pressure striving the air from the surrounding extra pleural tissue. ${ }^{5}$ In 2012, confronted with a high rate of pneumothorax, Ninane et al published a study on 37 subjects $^{6}$ who underwent partial occlusion of both upper lobes with spiration valves. The results underlined the safety of this procedure, but effectiveness was not proven. However, $24 \%$ of patients responded to an incomplete occlusion, and it is well demonstrated that a subset of patients does not have $\mathrm{CV}$ within segments ${ }^{7}$ confirming the possibility of achieving a first volume reduction with a subtotal treatment. Facing a similar threat with Zephyr valves, this study was based on a similar assumption: reduction of the intensity of the pathophysiologic mechanism suspected to create pneumothorax in order to lower its rate. Therefore, in order to reduce this complication while reaching EBV usual outcomes, we hypothesized that a two-step EBV implantation, during two distinct iterative procedures could lead to a more progressive target lobe volume reduction (TLVR) and thus ipsilateral lobe re-expansion, resulting in a significant decrease in the pneumothorax rate.

\section{Methods}

\section{Patients}

Between June 2018 and March 2020, 58 consecutive patients were included in this retrospective bi-center study carried out by Limoges ( 38 patients) and Toulouse (20 patients) University Hospitals. All patients met the inclusion criteria established by a BLVR expert panel: ${ }^{8}$ smoking cessation for at least 3 months, post bronchodilator forced expiratory volume in one-second (FEV1) less that $50 \%$ predicted value despite optimal medical management, significant static hyperinflation defined by a residual volume (RV) rated at least $175 \%$ predicted value, and a significant handicap characterized by a modified Medical research council (mMRC) score of 2 or more. All patients followed an optimal rehabilitation program prior to their inclusion. As initially recommended, ${ }^{8}$ lobar fissure integrity was determined by quantitative computed tomography with Strat $\mathrm{X}^{\circledR}$ (PulmonX
Corp., Redwood City, CA), with optional Chartis ${ }^{\circledR}$ assessment. CV was systematically measured using the Chartis ${ }^{\circledR}$ system in all patients enrolled after May 2019. ${ }^{9}$

\section{Ethical Considerations}

The bicenter retrospective study was performed in accordance with the principles stated in the declaration of Helsinki and approved by the Limoges Ethics Committee (number 319-2019-85). Written informed consent explaining the procedure and allowing the use of its data was obtained from all participants.

\section{Procedures and Follow-Up}

Based on encouraging preliminary results, ${ }^{10}$ all patients were treated following the strategy conceived in Limoges University Hospital. During the first procedure, EBVs were placed in all but the most proximal segment or subsegment (one segment or sub-segment left untreated in both RML and RUL lobe for RUL/RML treatments). Four weeks later, patients underwent a second procedure with EBV-implantation in the remaining segment(s) or sub-segment(s). For each procedure, patients were hospitalized for at least four days, including 24-hour strict bed rest immediately after EBV procedure. All patients had a complete evaluation before treatment, and 3 months after the second procedure. Forty-five (77\%) had a complete evaluation between the 2 steps including chest multi-detector computed tomography (MDCT) and plethysmography. Lobar volumes were measured on each MDCT using Thoracic VCAR software (GE Healthcare). Patients without any significant TLVR at 3 months after the final procedure underwent a re-bronchoscopy in order to adjust the placement or replace EBVs in case of air leak.

\section{Statistics}

The primary endpoint was the pneumothorax rate after both procedures. Secondary endpoints included median changes in $\mathrm{FEV}_{1}, \mathrm{RV}, 6$-minute walking test distance (6MWT), mMRC score and BODE Index, and the rate of other complications. Responder rates were also calculated based on established minimal clinically important differences (MCID): $15 \%$ or more increase in $\mathrm{FEV}_{1}, 430 \mathrm{~mL}$ or more decrease in $\mathrm{RV}^{11}$ an increase of at least $26 \mathrm{~m}$ in $6 \mathrm{MWT},{ }^{5}$ a decrease of at least 1 point on the mMRC score, ${ }^{12}$ a decrease of at least 1 point of the BODE Index. ${ }^{13}$ The MCID for target lobe volume reduction 
determined by high-resolution CT was $350 \mathrm{~mL}^{14,15}$ and $49 \%$ or more. $^{16}$

Safety data were available for all 58 patients. Efficacy data were available for all patients at baseline and after the 2nd procedure, and for 45 patients after the 1st procedure. No imputations were performed for missing data. All collected data were analysed using Statview software (SAS Institute, Inc., Cary, NC) and R software. Quantitative results are expressed as median [range] or mean \pm SD and qualitative results as $n(\%)$. Nominal variables were compared between groups using the chi-square or Fisher's exact test, as appropriate. Means were compared with the nonparametric Mann-Whitney $U$-test for continuous variables. For all analyses, $p<0.05$ defined significance.

\section{Results}

A median number of 5 EBVs (range 3 to 9) per subject were implanted. The distribution of the treated lobes was 39\% left upper lobe (LUL), 33\% left lower lobe (LLL), 14\% right upper and middle lobe (RUL and RML) and $8 \%$ right lower lobe (RLL). Forty-one patients had a homogeneous emphysema, including 5 panlobular emphysema due to alpha 1 antitrypsin deficiency, and 17 had a heterogeneous emphysema. The main results are reported in Table 1.

\section{Primary Outcome}

Only 4 pneumothoraxes (7\%) occurred during the study. Two pneumothoraces occurred after the first procedure. One patient was treated for RUL and RML resulting in complete atelectasis of the RML and a 31\% TLVR of the RUL. In the other case, EBV were implanted in the RUL resulting in its complete atelectasis. Two patients suffered from pneumothorax immediately after the second procedure. One of these patients was treated for the LUL leading to its complete atelectasis. The other one was treated for the RUL but had neither significant TLVR $(298 \mathrm{~mL}$ which corresponds to a reduction of $28 \%$ initial volume) nor changes in RV or FEV1. No late pneumothorax was

Table I Baseline Characteristics and Key Outcomes. Comparison with Randomized Controlled Trials Investigating EBVs

\begin{tabular}{|c|c|c|c|c|c|c|c|}
\hline & Current Study & $\begin{array}{l}\text { MCID Criteria } \\
n(\%)\end{array}$ & Believer-Hifi ${ }^{13}$ & Impact $^{10}$ & Stelvio'" & Liberate. $^{2}$ & Transform $^{8}$ \\
\hline $\begin{array}{l}\text { Baseline characteristics: } \\
\text { EBV, } \mathrm{n} \\
\text { FEVI } \pm \text { SD, \% predicted } \\
\text { TLC } \pm \text { SD, \% predicted } \\
\text { RV } \pm \text { SD, \% predicted } \\
\text { mMRC } \pm \text { SD } \\
6 M W T \pm S D, m \\
\text { BODE Score } \pm \text { SD } \\
\text { Valves, n (min-max) }\end{array}$ & $\begin{array}{l}58 \\
32.0 \pm 9.0 \\
133.0 \pm 14.9 \\
244.2 \pm 46.2 \\
3.0 \pm 0.7 \\
342 \pm 117 \\
5.9 \pm 1.6 \\
5(3-9)\end{array}$ & & $\begin{array}{l}25 \\
31.6 \pm 10.2 \\
132.0 \pm 12.0 \\
219.0 \pm 39.0 \\
4.0 \pm 1.0 \\
342 \pm 94 \\
N R \\
N R(N R)\end{array}$ & $\begin{array}{l}43 \\
28.4 \pm 6.3 \\
144.9 \pm 21.2 \\
277.3 \pm 55.2 \\
2.7 \pm 0.7 \\
308 \pm 91 \\
5.7 \pm 1.4 \\
4(\mathrm{NR})\end{array}$ & $\begin{array}{l}34 \\
29.0 \pm 7.0 \\
130.0 \pm 13.0 \\
216.0 \pm 36.0 \\
2.8 \pm 0.8 \\
372 \pm 90 \\
N R \\
4(2-7)\end{array}$ & $\begin{array}{l}128 \\
29.8 \pm 9.2 \\
139.0 \pm 18.9 \\
249.4 \pm 51.8 \\
3.0 \pm 0.8 \\
282 \pm 94 \\
6.1 \pm 1.7 \\
4(2-8)\end{array}$ & $\begin{array}{l}65 \\
28.0 \pm 7.4 \\
133.5 \pm 21.1 \\
224.5 \pm 42.4 \\
2.4 \pm 0.1 \\
311 \pm 81 \\
5.3 \pm 1.5 \\
4(2-8)\end{array}$ \\
\hline $\begin{array}{l}\text { Serious adverse events: } \\
\text { Pneumothorax n (\%) } \\
\text { COPD Exacerbation, n (\%) } \\
\text { Pneumonia, n (\%) }\end{array}$ & $\begin{array}{l}4(6.8) \\
8(13.7) \\
5(8.6)\end{array}$ & & $\begin{array}{l}2(8.0) \\
5(20.0) \\
2(8.0)\end{array}$ & $\begin{array}{l}12(27.0) \\
10(16.3) \\
0\end{array}$ & $\begin{array}{l}6(17.6) \\
4(11.7) \\
2(5.8)\end{array}$ & $\begin{array}{l}44(34.0) \\
10(7.8) \\
\mathrm{I}(0.8)\end{array}$ & $\begin{array}{l}15(23.0) \\
3(4.6) \\
3(4.6)\end{array}$ \\
\hline $\begin{array}{l}\text { Mean Change from } \\
\text { Baseline to 2nd procedure: } \\
\text { FEVI } \pm S D \text { \% predicted } \\
R V \pm S D . m L \\
6 M W T \pm S D \text {. meters } \\
\text { BODE Score } \pm S D \\
m M R C \pm S D\end{array}$ & $\begin{array}{l}19.6 \pm 25.0 \\
-468 \pm 960 \\
30.0 \pm 85.0 \\
-1.4 \pm 1.8 \\
-1.45 \pm 1.80\end{array}$ & $\begin{array}{l}30(51.7) \\
27(46.5) \\
30(51.7) \\
29(50.0) \\
51(87.9)\end{array}$ & $\begin{array}{l}8.8 \pm 15.8 \\
-260 \pm 240 \\
25.0 \pm 43.6 \\
N R \\
-0.52 \pm 0.43\end{array}$ & $\begin{array}{l}13.7 \pm 28.2 \\
-420 \pm 900 \\
22.6 \pm 66.6 \\
-0.7 \pm 1.5 \\
-0.39 \pm 1\end{array}$ & $\begin{array}{l}20.9 \pm 28.1 \\
-860 \pm 698 \\
60.0 \pm 71.6 \\
N R \\
N R\end{array}$ & $\begin{array}{l}17.2 \pm 27.9 \\
-490 \pm 830 \\
12.9 \pm 81.5 \\
-0.6 \pm 1.8 \\
-0.5 \pm 1.17\end{array}$ & $\begin{array}{l}20.7 \pm 29.6 \\
-660 \pm 1040 \\
36.2 \pm 76.9 \\
-0.97 \pm 2.0 \\
0.56 \pm 1.04\end{array}$ \\
\hline $\begin{array}{l}\text { Target Lobe Volume Reduction: } \\
\text { TLVR (\%) } \\
\text { TLVR (mL) } \\
\text { Complete Atelectasis, n (\%) }\end{array}$ & $\begin{array}{l}-50.6 \pm 35.1 \\
-802 \pm 609 \\
18(31)\end{array}$ & $\begin{array}{l}28(48.2) \\
43(74.1) \\
\text { NR }\end{array}$ & $\begin{array}{l}\text { NR } \\
\text { NR } \\
8(32)\end{array}$ & $\begin{array}{l}N R \\
N R \\
N R\end{array}$ & $\begin{array}{l}\mathrm{NR} \\
\mathrm{NR} \\
\mathrm{NR}\end{array}$ & $\begin{array}{l}-63.8 \pm 36.2 \\
-1142 \pm 702 \\
N R\end{array}$ & $\begin{array}{l}N R \\
-1090 \pm 620 \\
N R\end{array}$ \\
\hline
\end{tabular}

Abbreviations: SD, standard deviation; BMI, body mass index; FEVI, forced expiratory volume in Is; TLC, total lung capacity; RV, residual volume; TLCO, total lung capacity of $\mathrm{CO}$; $\mathrm{mL}$, milliliters, mMRC, modified medical research council; 6MWT, 6 minutes walking distance; HRCT, high-resolution computed tomography; LAV\%, lung volume attenuation of the untreated ipsilateral lobe/volume of the untreated ipsilateral lobe; NR, not reported; TLVR, target lobe volume reduction; T0, baseline characteristic; TI, results after the Ist procedure; T2, results after the 2 nd procedure; VUIL/ $\mathrm{VH}$, Volume of the untreated ipsilateral lobe to the volume of the hemithorax. 
seen. Three pneumothoraxes resolved within seven days with placement of a chest tube and without need for valve removal. One required one valve removal after 7 days, allowing for chest tube weaning. Of the 4 patients experiencing pneumothoraxes, 3 had heterogeneous (3/17, $17.6 \%)$ and 1 had homogeneous $(1 / 41,2.4 \%)$ emphysema. No statistical difference between patients with and without pneumothorax was found regarding main baseline characteristics (Table 2).

At the 3-month follow-up, other complications were pneumonia and severe COPD exacerbation $(8.6 \%$ and $13.7 \%$ of patients, respectively). A re-bronchoscopy was required for $20.7 \%$ of patients.

\section{Secondary Outcomes}

MCID criteria (Table 1) were reached after both procedures for $\mathrm{FEV}_{1}(+19.6 \pm 25 \%)$, RV $(-468 \pm 960 \mathrm{~mL})$, 6MWT $(30 \pm 85 \mathrm{~m})$, BODE Index $(-1.4 \pm 1.8$ point $)$ and TLVR $(50.6 \pm 35.1 \%)$. Significant TLVR (MCID) was obtained in $74.1 \%$ of patients $(43 / 58)$.

Complete intermediate evaluations were available for 45 patients (Table 3, Figure 1). Mean TLVR after the first procedure was measured at $511 \pm 554 \mathrm{~mL}(38.8 \pm 36.9 \%)$. Twelve patients $(28.5 \%)$ obtained a TLVR of $350 \mathrm{~mL}$ or more after the first procedure (Figure 2). In this population, median change after the first procedure was $21.3 \pm$ $24.4 \%$ for FEV1, $595 \pm 774 \mathrm{~m}$ for RV, $7.5 \pm 15$ for $6 \mathrm{MWT}$ and $0.9 \pm 0.6$ for mMRC score. By choosing to define a response to treatment as a TLVR of $350 \mathrm{~mL}$ or more, we identified 4 patterns of response (Figure 1): i) For "Great responders" both procedures resulted in significant $\operatorname{TLVR}(8 / 45,17.8 \%)$ with a median FEV1 increase of 33.6 and a median TLVR rated at $1358 \mathrm{~mL}$; ii) "Early responders" $(4 / 45,8.9 \%)$ only reached a TLVR of more than $350 \mathrm{~mL}$ after the first procedure (median FEV1 increase $35.2 \%$ and median TLVR $618 \mathrm{~mL}$ ), iii) In the "Late responders" group $(22 / 45,48.9 \%)$ there was no significant TLVR after the first procedure unlike the second procedure (median FEV1 increase $+21.1 \%$, median TLVR $851 \mathrm{~mL}$ ), iv) "Non-responders" did not have a significant TLVR after either procedure (14/45, 31.1\%). Combining the two populations with an initial TLVR ("Great" and "Early" responders, $\mathrm{n}=12 / 45,26.7 \%$ ), median change for $\mathrm{FEV}_{1}$ was $+21.3( \pm 24.4 \%)$ after the first procedure, and $+34.1 \%$ after complete treatment, significantly greater than in the two groups with no initial TLVR $(+15.5 \%, p=0.01)$. Of note, regarding the baseline characteristics of the population, no difference was found between the different patterns of response.

\section{Discussion}

This two-step procedure allows for a more progressive shifting of lung volumes in a subset of patients (approximately one-third) and may decrease pneumothorax rates without compromising treatment effectiveness. The baseline characteristics of our population are similar to those found in previously published trials $\mathrm{s}^{3,12,14,17,18}$ especially for RV usually mentioned as a risk factor for EBV-induced pneumothorax. Data regarding the predictive factors for pneumothorax reported by Gompelmann et al ${ }^{4}$ were available for all patients treated in Limoges University Hospital $(n=39)$. Results were similar with a high ratio of low attenuation volume of the target lobe to target lobe volume (LAV\%) (44.7\% vs 37\%), a similar percentage of pleural

Table 2 Baseline Characteristics of the Pneumothorax Population

\begin{tabular}{|l|c|c|c|}
\hline & Pneumothorax & No Pneumothorax & P \\
\cline { 2 - 4 } & (4 Patients) & (54 Patients) & \\
\hline Baseline characteristics: & & & 0.17 \\
EBV, n (min-max) & $4(3-6)$ & $5(2-9)$ & 0.98 \\
FEVI \pm SD, \% predicted & $30.0 \pm 6.9$ & $31.0 \pm 9.0$ & 0.81 \\
TLC \pm SD, \% predicted & $124.0 \pm 16.7$ & $134.0 \pm 14.7$ & 0.28 \\
RV \pm SD, \% predicted & $222.0 \pm 33.1$ & $246 \pm 46.8$ & 1.00 \\
mMRC \pm SD & $3.0 \pm 1.1$ & $3.0 \pm 0.6$ & 0.99 \\
6MWT \pm SD, m & $348.0 \pm 98.2$ & $342.0 \pm 119.2$ & 0.84 \\
BODE Score \pm SD & $6 \pm 0.9$ & $6.0 \pm 1.7$ & 0.07 \\
Homogeneous Emphysema, n (\%) & $1(2.5)$ & $40(97.5)$ & $14(82.4)$ \\
Heterogeneous emphysema, n (\%) & $3(17.6)$ & \\
\hline
\end{tabular}

Abbreviations: SD, standard deviation; FEVI, forced expiratory volume in Is; TLC, total lung capacity; RV, residual volume; mL, milliliters, $\mathrm{mMRC}$, modified medical research council; 6MWT, 6 minutes walking distance. 
Table 3 Overall Population and Subgroup Analysis Based on Evolution of Target Lobe Volume $>350 \mathrm{~mL}$ at Ist Procedure

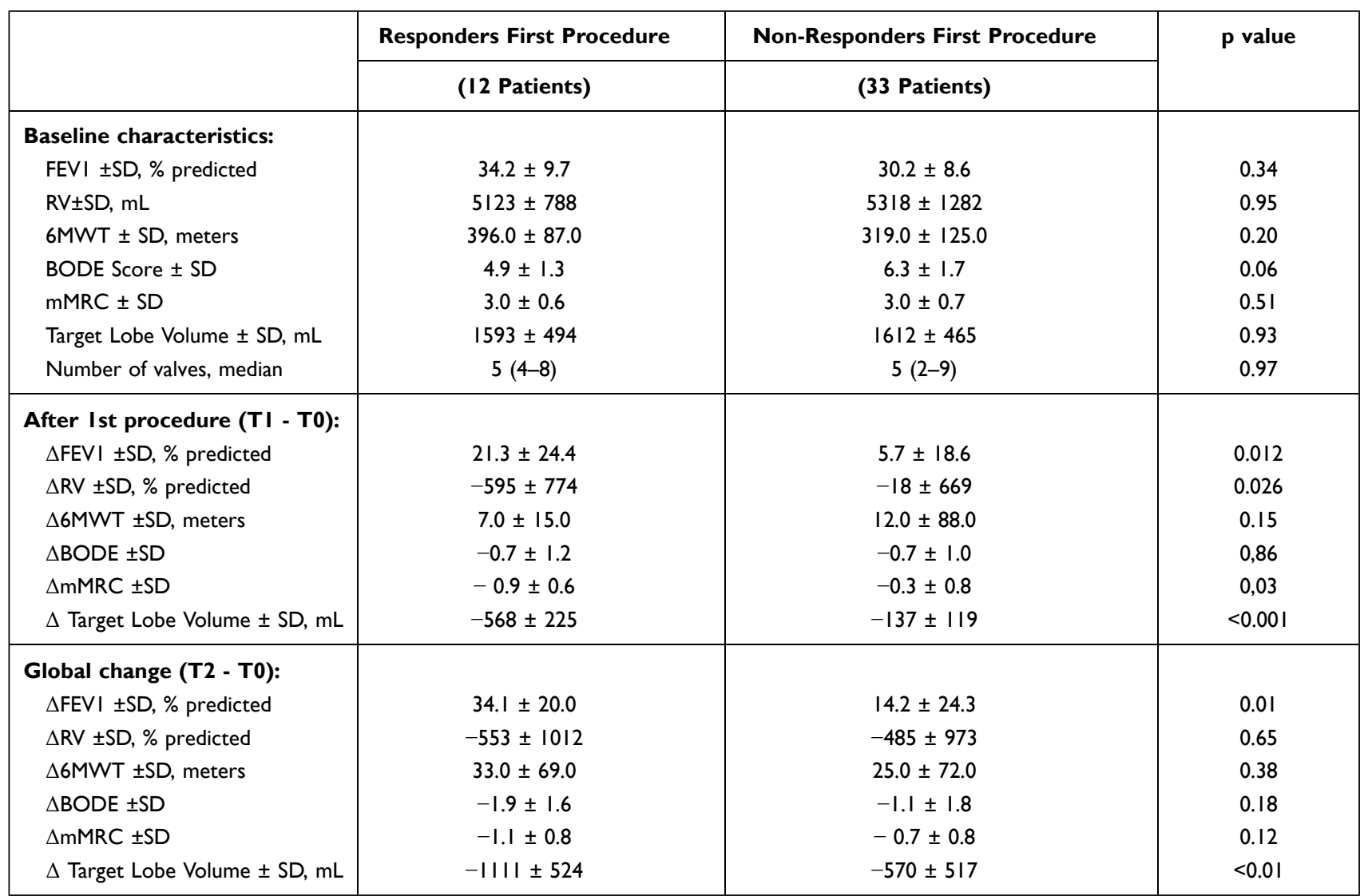

Abbreviations: SD, standard deviation; BMI, body mass index; FEVI, forced expiratory volume in Is; TLC, total lung capacity; RV, residual volume; TLCO, total lung capacity of CO; mMRC, modified medical research council; 6MWT, 6 minutes walking distance; HRCT, high-resolution computed tomography; LAV\%, lung volume attenuation of the untreated ipsilateral lobe/volume of the untreated ipsilateral lobe; $\mathrm{mL}$, milliliter; NR, not reported; VUIL/VH, Volume of the untreated ipsilateral lobe to the volume of the hemithorax; T0, baseline; TI, after the first procedure; T2, after the 2nd procedure; $\Delta$, difference.

adhesions (47\% vs $41.3 \%$ ) and a high ratio of volume of untreated ipsilateral lobe to volume of hemithorax (VUIL/ VH) (39\% vs 47\%). Therefore, we did not find any unexpected factors when interpreting pneumothorax rates in this study.

When comparing to previous published studies using Zephyr $^{\circledR}$ EBV in a single procedure, only two reported a pneumothorax rate less than $10 \%{ }^{17,19}$ The main explanation for the low pneumothorax rate in these studies may be the inclusion criteria regarding collateral ventilation. In particular, in the Believer study, ${ }^{17}$ StratX was not available, and Chartis not mandatory and inclusion was only based on MDCT assessment by 2 radiologists, likely resulting in the inclusion of $\mathrm{CV}+$ patients, and subsequently in a low pneumothorax rate but also poor outcomes in terms of FEV1 $(8.8 \pm 15.5 \%)$, 6MWD $(25.0 \pm$ $43.6 \mathrm{~m})$ and $\mathrm{RV}(260 \pm 240 \mathrm{~mL})$. However, with two distinct procedures, this treatment algorithm seemed to slightly increase the rate of pneumonia (Believer $8 \%,{ }^{17}$ Stelvio $5.8 \%{ }^{15}$ Liberate $0.8 \%{ }^{3}$ Transform $4.6 \%{ }^{12}$ ). Of note, the rate of severe COPD exacerbations per patient was limited to $13.7 \%(8 / 58)$, similar to what was reported in the Liberate ${ }^{3}$ and Stelvio trials. ${ }^{15}$

Even if there is no single follow-up criterion to define a responder after EBV treatment, TLVR seem to be the most reproducible and, moreover, the most representative of Zephyr ${ }^{\circledR}$ EBV objectives. According to Gompelmann et al, ${ }^{16}$ a TLVR between $49 \%$ and $54 \%$ should be used when interpreting a clinical relevance threshold. In our study, TLVR is comparable to other published data, ${ }^{3,12}$ with a majority of patients reaching the $\mathrm{MCID}^{16}$ for this criteria. This translates into a similar magnitude of benefits compared to previous clinical trials in terms of $\mathrm{FEV}_{1}, \mathrm{RV}$ and 6MWD (Table 1)..$^{3,12,14,17,18}$ Our interim analysis between the two procedures shows that a subgroup of patients (26.7\%) reached a TLVR greater than or equal to $350 \mathrm{~mL}$, usually reported as a relevant threshold. ${ }^{14,20,21}$ In this population, TLVR translates into clinically relevant improvement in $\mathrm{FEV}_{1}, \mathrm{RV}$ and mMRC score despite incomplete occlusion. Stratifying patients 


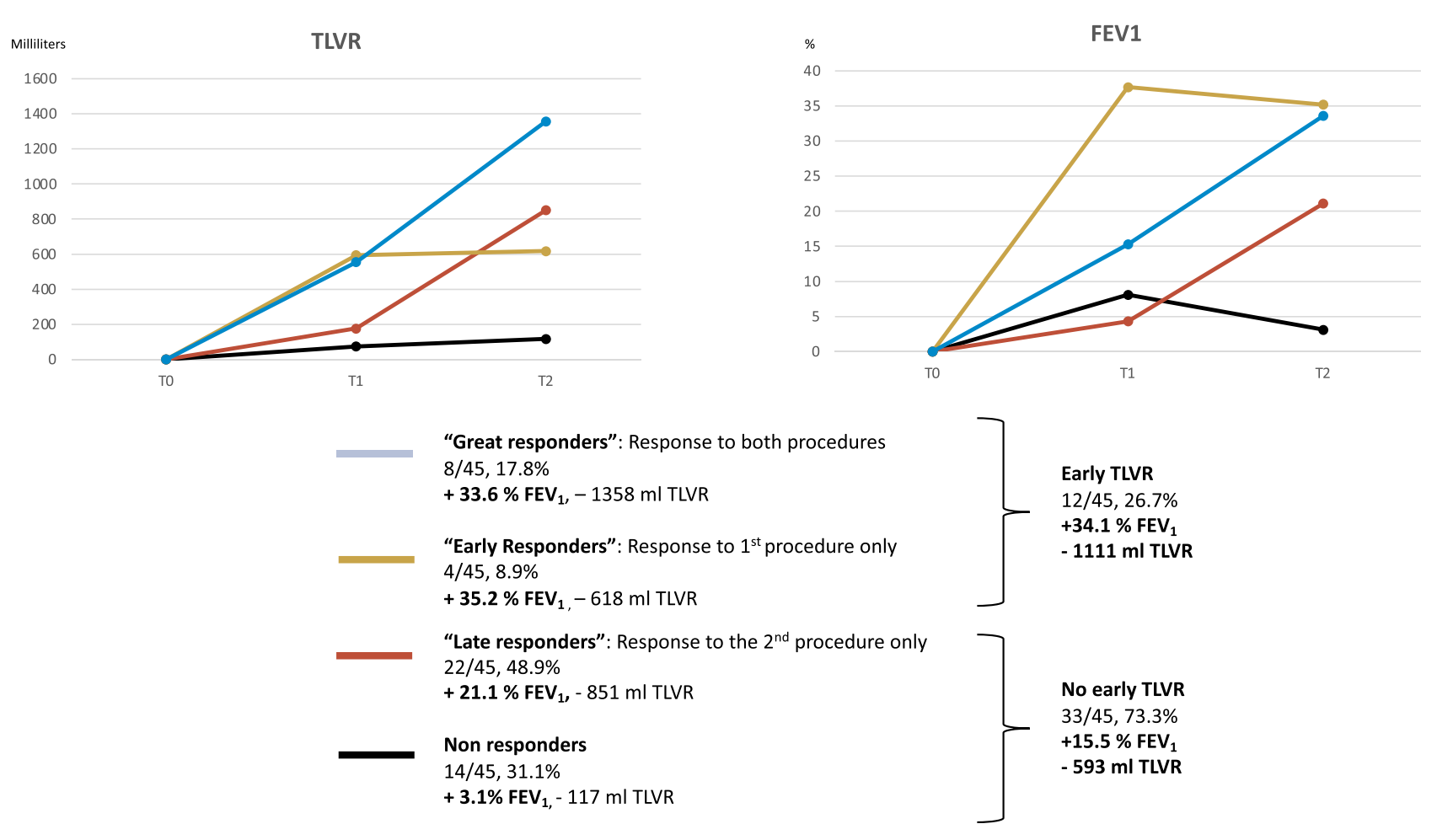

Figure I Response patterns to two step EBV treatment and main outcomes for each population. Abbreviations: T0, baseline; T1, first procedure; T2, second procedure.

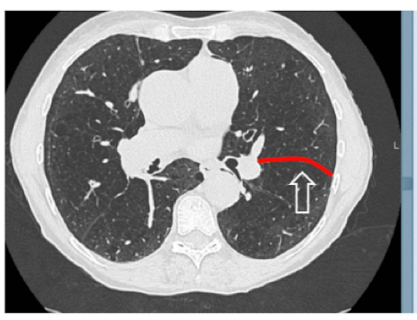

Baseline :

- $\mathrm{FEV} 1=790 \mathrm{~mL}$

- $\mathrm{RV}=7670 \mathrm{~mL}$

- $\quad$ LUL Volume $=1472 \mathrm{~mL}$

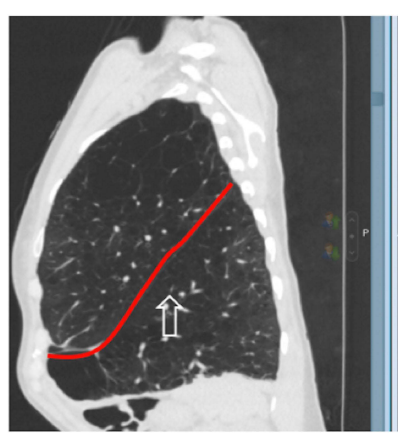

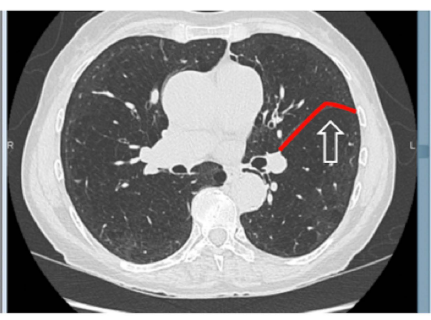

After the $1^{\text {st }}$ procedure :

- $\mathrm{FEV} 1=950 \mathrm{~mL}$

- $\mathrm{RV}=6120 \mathrm{~mL}$

- $\quad$ LUL Volume $=936 \mathrm{~mL}$

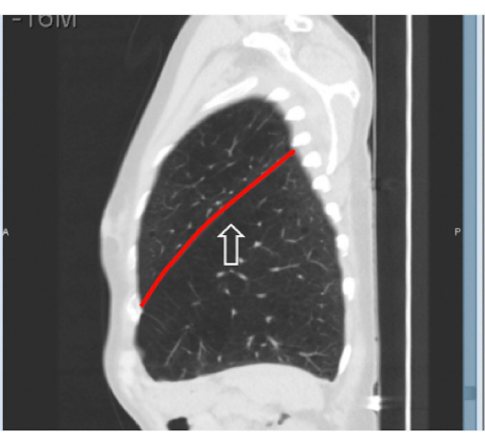

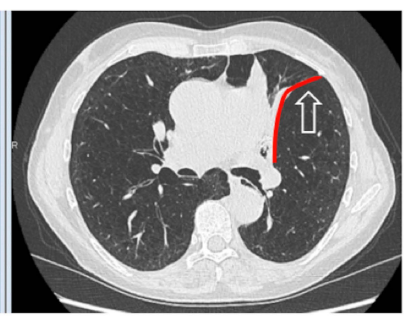

After the $2^{\text {nd }}$ procedure :

- $\quad \mathrm{FEV} 1=1070 \mathrm{~mL}$

- $\mathrm{RV}=4550 \mathrm{~mL}$

- $\quad$ LUL Volume $=56 \mathrm{~mL}$

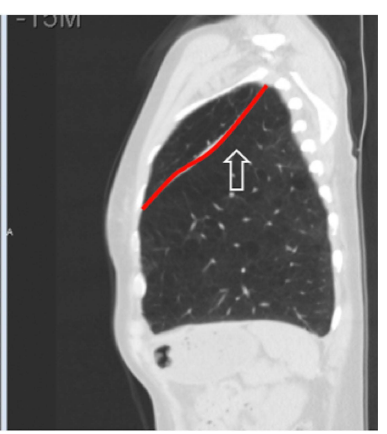

Figure 2 Example of a "Great responder" patient with progressive lung volume reduction on CT-scan resulting in a progressive decrease in RV and a progressive improvement in FEVI.

Abbreviations: FEVI, forced expiratory volume in Ist second; RV, residual volume; LUL volume, Left Upper Lobe Volume. 
on a $350 \mathrm{~mL}$ TLVR after the first procedure (Table 3 , Figure 1) demonstrates that patients who reached pneumoreduction after the initial procedure, also have a statistically better outcome for FEV1 (34.1 vs 15.5\%, $p=0.01)$ after complete lobar occlusion. Moreover, as EBV treatment is indicated for patients with little to no collateral ventilation, ${ }^{22}$ the difference between the "Late" and "Early" responders might be explained by the presence or absence of collateral ventilation between the subsegments treated and the subsegments which remain ventilated after the first procedure. Consequently, as intersegmental collateral ventilation is not always present, ${ }^{7}$ there is a strong need to design new tools for intersegmental collateral ventilation assessment (optimization of StratX software, Chartis balloon suited for segmental approach). This would allow physicians to be more predictive in obtaining this initial TLVR and identify patients who will benefit from a two-step treatment. Also, the possible intersegmental collateral ventilation may permit a more targeted treatment in patients with heterogeneity within the target lobe, sparing the most functional segments. However, we think that intersegmental collateral ventilation may not be the only physiological parameter to be taken in account when interpreting TLVR after each procedure as a subgroup of "Great Responders" seems to emerge. More research is needed to explain that response pattern.

In our study, $31 \%$ of patients reached complete atelectasis, similar to what was reported in previous publications. ${ }^{17,23}$ The relation between lobar occlusion and clinical efficacy has been underlined in different studies. $^{24,25}$ However, complete atelectasis is also associated with pneumothorax. ${ }^{4}$ Therefore, we think that our results reinforce not only the idea that the high pneumothorax rate observed in clinical trials is related to a brutal and complete lobar occlusion but also, through our intermediate evaluation, that a progressive volume reduction is possible, and could decrease the risk of this complication.

This study has some limitations. It is retrospective and there is no control arm. Hence, no definitive conclusions can be drawn from this uncontrolled study, but these results are consistent with the ones previously presented by Limoges University Hospital on a smaller population. ${ }^{10}$ The intermediate analysis strongly supports the fact that a susbset of patients should be targeted by new tools. Moreover, there is no medico-economic evaluation of this strategy which could be a very important concern.
On one hand, this two-step approach does not seem to save costs as all patients are admitted for two stays. On the other hand, it could be cost-effective by reducing the rate of a frequent and potentially life-threatening complication. Furthermore, if a dedicated Chartis could identify patients with no intersegmental ventilation, this approach could only be proposed to this subset of patients (one-third approximately), limiting additional procedures and hospitalizations.

Altogether, our results suggest that: i) a suboptimal treatment after the first procedure results an initial lung volume reduction in a subset of patients, a more progressive shift in lung volume (still leading to an efficient atelectasis), and thus a decreased pneumothorax rate; ii) Some patients reach some MCID despite infralobar treatment, likely due to intersegmental fissures and should be targeted by new tools.

In conclusion, this new approach using EBV could reduce the incidence of pneumothorax and does not seem to increase other complication rates. Clinical and physiological outcomes are similar to those reported in studies using the conventional single-step treatment. Additional research is needed to better characterize this subpopulation before treatment to avoid a two-procedure approach in "late responders". Moreover, these results should be validated through a randomized prospective study comparing the two strategies in a larger population.

\section{Consent Statement}

The protocol was approved by Limoges University Ethics Committee.

\section{Take Home Message}

A two-step bronchoscopic lung volume reduction procedure with endobronchial valves significantly decreased the pneumothorax rate, without increasing other complication rates and with similar positive outcomes compared a conventional one-step approach.

\section{Author Contributions}

All authors made a significant contribution to the work reported, whether that is in the conception, study design, execution, acquisition of data, analysis and interpretation, or in all these areas; took part in drafting, revising or critically reviewing the article; gave final approval of the version to be published; have agreed on the journal to which the article has been submitted; and agree to be accountable for all aspects of the work. 


\section{Funding}

This study was not supported by any grant.

\section{Disclosure}

Dr Egenod reports personal fees from ASTRA ZENECCA, BOEHRINGER INGELHEIM, NOVARTIS, PulmonX and Olympus, outside the submitted work. Prof. Dr. Boris Melloni reports personal fees, non-financial support from Astra-Zeneca, Boehringer Ingelheim France, Chiesi France, Menarini France, Novartis France, GSK France, outside the submitted work. The authors report no other conflicts of interest in this work.

\section{References}

1. Labarca G, Uribe JP, Pacheco C, et al. Bronchoscopic lung volume reduction with endobronchial zephyr valves for severe emphysema: a systematic review and meta-analysis. Respiration. 2019;98 (3):268-278. doi:10.1159/000499508

2. Neumeier A, Keith R. Clinical guideline highlights for the hospitalist: the GOLD and NICE guidelines for the management of COPD. J Hosp Med. 2020;15(4):240-241. doi:10.12788/jhm.3368

3. Criner GJ, Sue R, Wright $\mathrm{S}$, et al. A multicenter randomized controlled trial of zephyr endobronchial valve treatment in heterogeneous emphysema (LIBERATE). Am J Respir Crit Care Med. 2018;198 (9):1151-1164. doi:10.1164/rccm.201803-0590OC

4. Gompelmann D, Lim H-J, Eberhardt R, et al. Predictors of pneumothorax following endoscopic valve therapy in patients with severe emphysema. Int J Chron Obstruct Pulmon Dis. 2016;11:1767-1773. doi: $10.2147 /$ COPD.S106439

5. Valipour A, Slebos D-J, de Oliveira HG, et al. Expert statement: pneumothorax associated with endoscopic valve therapy for emphysema--potential mechanisms, treatment algorithm, and case examples. Respiration. 2014;87(6):513-521. doi:10.1159/000360642

6. Ninane V, Geltner C, Bezzi M, et al. Multicentre European study for the treatment of advanced emphysema with bronchial valves. Eur Respir J. 2012;39(6):1319-1325. doi:10.1183/09031936.00019711

7. Gompelmann D, Eberhardt R, Herth FJF. Collateral ventilation. Respiration. 2013;85(6):515-520. doi:10.1159/000348269

8. Herth FJF, Slebos D-J, Criner GJ, Valipour A, Sciurba F, Shah PL. Endoscopic lung volume reduction: an expert panel recommendation - update 2019. Respiration. 2019;97(6):548-557. doi:10.1159/ 000496122

9. Klooster K, Koster TD, Glösenkamp CR, et al. Chartis measurement is of additional diagnostic value to CT fissure completeness score for the assessment of endobronchial valve treatment in severe emphysema. In: B16. Advances in Interventional Pulmonary. American Thoracic Society International Conference Abstracts. American Thoracic Society; 2019:A2633-A2633. doi:10.1164/ ajrccm-conference.2019.199.1_MeetingAbstracts.A2633

10. Egenod T, Delacourt N, Simonneau Y, Vergnenègre A, Melloni B, Dusselier M. Endobronchials valves: impact of the 2 step approach on pneumothorax rates. In: D45. Invasive Pulmonary Procedures: Diagnosis, Treatment, and Complications. American Thoracic Society International Conference Abstracts. American Thoracic Society; 2020:A6867-A6867. doi:10.1164/ajrccm-conference. 2020.201.1_MeetingAbstracts.A6867
11. Hartman JE, Ten Hacken NHT, Klooster K, Boezen HM, de Greef MHG, Slebos D-J. The minimal important difference for residual volume in patients with severe emphysema. Eur Respir J. 2012;40(5):1137-1141. doi:10.1183/09031936.00219111

12. Kemp SV, Slebos D-J, Kirk A, et al. A multicenter randomized controlled trial of zephyr endobronchial valve treatment in heterogeneous emphysema (TRANSFORM). Am J Respir Crit Care Med. 2017;196(12):1535-1543. doi:10.1164/rccm.201707-1327OC

13. Martinez FJ, Han MK, Andrei A-C, et al. Longitudinal change in the BODE index predicts mortality in severe emphysema. Am J Respir Crit Care Med. 2008;178(5):491-499. doi:10.1164/rccm.200709$1383 \mathrm{OC}$

14. Valipour A, Slebos D-J, Herth F, et al. Endobronchial valve therapy in patients with homogeneous emphysema. Results from the IMPACT Study. Am J Respir Crit Care Med. 2016;194 (9):1073-1082. doi:10.1164/rccm.201607-1383OC

15. Klooster K, Ten Hacken NHT, Hartman JE, Kerstjens HAM, van Rikxoort EM, Slebos D-J. Endobronchial valves for emphysema without interlobar collateral ventilation. $N$ Engl J Med. 2015;373 (24):2325-2335. doi:10.1056/NEJMoa1507807

16. Gompelmann D, Kontogianni K, Schuhmann M, Eberhardt R, Heussel C, Herth F. The minimal important difference for target lobe volume reduction after endoscopic valve therapy. Int J Chron Obstruct Pulmon Dis. 2018;13:465-472. doi:10.2147/COPD. S152029

17. Zoumot Z, Davey C, Jordan S, et al. A Randomised Controlled Study of bronchoscopic lung volume reduction with endobronchial valves for patients with heterogeneous emphysema and intact interlobar fissures: the BeLieVeR-HIFi Study. NIHR Journals Library; 2015. Available from: http://www.ncbi.nlm.nih.gov/books/NBK316148/. Accessed July 4, 2017.

18. Klooster K, Hartman JE, Ten Hacken NHT, Slebos D-J. One-year follow-up after endobronchial valve treatment in patients with emphysema without collateral ventilation treated in the STELVIO trial. Respiration. 2017;93(2):112-121. doi:10.1159/000453529

19. Fiorelli A, Santoriello C, De Felice A, et al. Bronchoscopic lung volume reduction with endobronchial valves for heterogeneous emphysema: long-term results. $J$ Vis Surg. 2017;3:170. doi:10.21037/jovs.2017.10.04

20. Gompelmann D, Eberhardt R, Slebos D-J, et al. Diagnostic performance comparison of the chartis system and high-resolution computerized tomography fissure analysis for planning endoscopic lung volume reduction. Respirology. 2014;19(4):524-530. doi:10.1111/ resp. 12253

21. Schuhmann M, Raffy P, Yin Y, et al. Computed tomography predictors of response to endobronchial valve lung reduction treatment. comparison with chartis. Am J Respir Crit Care Med. 2015;191 (7):767-774. doi:10.1164/rccm.201407-1205OC

22. Sciurba FC, Ernst A, Herth FJF, et al. A Randomized Study of endobronchial valves for advanced emphysema. $N$ Engl $J$ Med. 2010;363(13):1233-1244. doi:10.1056/NEJMoa0900928

23. Gompelmann D, Heinhold T, Rötting M, et al. Long-term follow up after endoscopic valve therapy in patients with severe emphysema. Ther Adv Respir Dis. 2019;13:1753466619866101.

24. Herth FJF, Noppen M, Valipour A, et al. Efficacy predictors of lung volume reduction with zephyr valves in a European cohort. Eur Respir J. 2012;39(6):1334-1342. doi:10.1183/09031936.00161611

25. Hopkinson NS, Kemp SV, Toma TP, et al. Atelectasis and survival after bronchoscopic lung volume reduction for COPD. Eur Respir J. 2011;37(6):1346-1351. doi:10.1183/09031936.00100110 


\section{Publish your work in this journal}

The International Journal of COPD is an international, peer-reviewed journal of therapeutics and pharmacology focusing on concise rapid reporting of clinical studies and reviews in COPD. Special focus is given to the pathophysiological processes underlying the disease, intervention programs, patient focused education, and self management

protocols. This journal is indexed on PubMed Central, MedLine and CAS. The manuscript management system is completely online and includes a very quick and fair peer-review system, which is all easy to use. Visit http://www.dovepress.com/testimonials.php to read real quotes from published authors.

Submit your manuscript here: https://www.dovepress.com/international-journal-of-chronic-obstructive-pulmonary-disease-journal 